\title{
Avaliação da higiene e condições do ambiente de processamento de um pastifício
}

A manutenção de condições higiênico-sanitárias adequadas durante o processo de fabricação é indispensável para garantir a saúde do consumidor e o destaque dos empreendimentos alimentícios. A implementação de programas de boas práticas de fabricação pode assegurar a manutenção da qualidade e segurança dos alimentos. Objetivou-se avaliar as boas práticas de fabricação e classificar de acordo com a RDC 275/02 uma agroindústria de pastifício que opera no Oeste do estado do Paraná, estabelecendo uma relação com a avaliação microbiológica de superfícies, equipamentos e ambiente. A empresa após a avaliação foi classificada no Grupo 2, atendendo a $58 \%$ dos itens avaliados. As não conformidades foram relacionadas aos resultados das análises microbiológicas e com base no observado, foram sugeridas possíveis melhorias a serem adotadas pela agroindústria, possibilitando a sua subida de nível na classificação bem como melhoria na qualidade de seus serviços e produção. Ações de extensão universitária como essas podem levar a ampliação da capacitação técnica por meio do fornecimento de treinamento e informações aos proprietários e funcionários das empresas, ampliando a divulgação do conhecimento científico. Dessa forma, este estudo foi de grande valia, para a empresa acompanhada, para outras empresas do ramo, para o meio científico e acadêmico, que com a leitura deste estudo de caso poderão verificar na prática a avaliação de um estabelecimento produtor de alimentos, e levar em conta as muitas possibilidades de melhoria apresentadas, com vistas a atingir a excelência na tão almejada qualidade.

Palavras-chave: Epidemiologia; Gestão da qualidade; Higiene.

\section{Evaluation of hygiene and conditions of the environment for processing a pastifice}

\begin{abstract}
The adequate maintenance of hygienic-sanitary conditions during the manufacturing process is indispensable to ensure the consumer health and the highlight of the food enterprises. The implementation of good manufacturing practice programs can ensure the maintenance of quality and food safety. It was intended to evaluate good manufacturing practices and classify in accordance with RDC 275/02 a manufacturing industry of masses located in west of the Paraná state, establishing a relationship with the microbiological evaluation of surfaces, equipment and environment. The company after the evaluation was classified in second Group, serving $58.57 \%$ of the items evaluated. Non-conformances were related to the results of microbiological analyses and based on the observed, it was suggested possible improvements to be adopted by the agroindustry, enabling its rise in the level of classification as well as improvement in the quality of its services and production. University extension actions like these can lead to the expansion of technical training through the provision of training and information to the owners and employees of companies, expanding the dissemination of scientific knowledge. Thus, this study was of great value, for the accompanied company, for other companies in the industry, for the scientific and academic milieu, which with the reading of this case study will be able to verify in practice the evaluation of a food producing establishment and take into account the many possibilities for improvement presented, with a view to achieving excellence in the longed for quality.
\end{abstract}

Keywords: Epidemiology; Quality management; Hygiene.

Carla Adriana Pizarro Schmidt (iD Universidade Tecnológica Federal do Paraná, Brasil http://lattes.cnpq.br/6715272307281643

http://orcid.org/0000-0003-4098-5759 carlaschmidt@utfpr.edu.br

\section{Camila Ciello (iD)}

Universidade Tecnológica Federal do Paraná, Brasil http://lattes.cnpq.br/2659608321846143

http://orcid.org/0000-0001-6842-5716 camila ciello@outlook.com

Gabriela Fernandes Anversi (1)

Universidade Tecnológica Federal do Paraná, Brasil http://lattes.cnpq.br/1619216854744796 http://orcid.org/0000-0003-0380-8331 gabianversi@outlook.com
Valéria Cristina Gonçalves (iD

Universidade Tecnológica Federal do Paraná, Brasil http://lattes.cnpq.br/7225625741566347

http://orcid.org/0000-0002-8012-8922 valeria.goncalves7@hotmail.com

Vanesa Cristina Slongo

Universidade Tecnológica Federal do Paraná, Brasil http://lattes.cnpq.br/5426258773529313 http://orcid.org/0000-0002-0911-443X vanessa.slongo@hotmail.com

\section{Gabrieli Beatriz Ferronatto it}

Universidade Tecnológica Federal do Paraná, Brasil http://lattes.cnpq.br/3377388301008933 http://orcid.org/0000-0002-2089-8597 gabrielinatto@gmail.com
Edward Seabra Junior (iD

Universidade Tecnológica Federal do Paraná, Brasil http://lattes.cnpq.br/2722201569762562

http://orcid.org/0000-0002-5562-6612 seabra.edward@gmail.com

\section{Celeide Pereira (iD)}

Universidade Tecnológica Federal do Paraná, Brasil http://lattes.cnpq.br/0241268307864526

http://orcid.org/0000-0001-9549-5410 celeide@utfpr.edu.br

\section{Valdemar Padilha Feltrin (iD}

Universidade Tecnológica Federal do Paraná, Brasil http://lattes.cnpq.br/6941098938711952 http://orcid.org/0000-0002-4459-2947 feltrin@utfpr.edu.br

Referencing this:

SCHMIDT, C. A. P.; CIELLO, C.; ANVERSI, G. F.; GONÇALVES, V. C.; SLONGO, V. C.; FERRONATTO, G. B.; SEABRA JUNIOR, E.; PEREIRA, C.; FELTRIN, V. P.. Avaliação da higiene e condições do ambiente de processamento de um pastifício. Revista Ibero Americana de Ciências Ambientais, v.12, n.1, p.126-138, 2021. DOI: 


\section{INTRODUÇÃO}

A agroindústria brasileira é um setor próspero que superou grandes desafios nos últimos anos, gerando divisas e empregos. O conceito de agroindústria diz respeito a indústrias que se dedicam à transformação e ao processamento de matérias-primas agropecuárias (de origem animal e vegetal). A agroindústria é o conjunto de atividades relacionadas à transformação de matérias-primas provenientes da agricultura, pecuária, aquicultura ou silvicultura (LOURENÇO, 2010).

A segurança dos alimentos requer o monitoramento constante dos produtos alimentícios para garantir que os mesmos se encontrem livres de patógenos. Os microrganismos desempenham papéis importantes na indústria alimentícia, incluindo a deterioração de alimentos. Entretanto, nem todos os microrganismos encontrados em alimentos provocam efeitos danosos nesses produtos, ou naqueles que os ingerem. Muitos são desejáveis e até mesmo essenciais como aqueles que crescem em alimentos fermentados (MADIGAN et al., 2016).

Os pães são um bom exemplo de produtos fermentados que são obtidos da farinha de trigo ou outras farinhas, adicionados de líquido, podendo conter outros ingredientes; enquanto que as massas alimentícias, são produtos obtidos da farinha de trigo e ou de outros cereais, leguminosas, raízes e ou tubérculos, resultantes do processo de empasto e amassamento mecânico, sem fermentação (BRASIL, 2005).

O complexo agroalimentar do trigo envolve a produção e transformação dos grãos de trigo e a sua distribuição na forma de farinhas, pães e massas (TOLEDO et al., 2000). Deina et al. (2018), ao estudarem estatisticamente o cenário agrícola do trigo no estado do Paraná, observaram um comportamento estacionário, ou seja, a tendência de plantio e colheita desse produto entre os anos de 2004 a 2016 foi constante, apresentando ainda previsão de continuar da mesma forma para os anos seguintes, ou seja, a principal matéria prima para produção de massas e pães não apresenta previsão de aumento de produção nesse estado, o qual, de acordo com o estudo, é responsável por $53 \%$ da área cultivada com trigo no Brasil. Isso acaba por nos esclarecer que a importação desse cereal acabará tendo que ser ampliada caso a indústria de pastifício venha a crescer, pois isso de certa forma é a tendência normal do segmento, tendo em vista que de acordo com Dantas et al. (2012), as massas alimentícias desempenham um importante papel no mercado de produtos alimentícios devido a facilidade da obtenção da matéria prima, simplicidade do processo de produção, baixo custo, além do seu valor nutricional.

Diante da crescente valorização do setor de alimentação coletiva e da alta competitividade, a preocupação com a qualidade sanitária e nutricional alimentícia é fundamental para garantir o destaque do estabelecimento, devido a melhoria da qualidade dos produtos oferecidos (FONSECA et al., 2010). A qualidade é uma vantagem competitiva importante. Para as indústrias agroalimentares ela é uma questão de sobrevivência. Um problema de não-qualidade pode afetar, de maneira importante, a imagem de uma marca consolidada no mercado (TOLEDO et al., 2000).

As boas práticas de fabricação são procedimentos que devem ser adotados pelas agroindústrias com o objetivo de garantir a qualidade higiênico-sanitária dos alimentos de acordo com a legislação vigente 
(ANVISA, 2004). Segundo Guarienti et al. (2007), a manutenção de condições higiênico-sanitárias adequadas na agroindústria é fundamental para assegurar a saúde do consumidor e a garantia de sucesso do empreendimento. Forsythe (2013), afirmam que a qualidade e segurança nas agroindústrias podem ser garantidas através da implementação do programa de boas práticas de fabricação, que visa o fornecimento de alimentos inócuos a população.

Como o mercado consumidor busca qualidade, as boas práticas de Fabricação estreitam a relação com o ser humano que atua nos processos envolvidos, assegurando sua saúde, segurança e bem-estar, conferindo a ele educação e qualificação nos aspectos de higiene, sanitização, desinfecção e disciplina operacional (GOMES et al., 2006). Vialta et al. (2002), complementam que a técnica pode ainda trazer melhoria de qualidade e redução de custos. Os autores relatam ainda casos de redução de custos iniciais de 15 a $20 \%$, chegando a $40 \%$ depois de certo período. Sendo assim, Silva Júnior (2001), define as boas práticas como normas e procedimentos que visam atingir um determinado padrão de identidade e qualidade de um produto e/ou serviços no ramo alimentício, cuja eficácia e efetividade devem ser avaliadas através de inspeção e/ou investigação.

A implantação desse sistema preconiza a aplicação de medidas corretivas e o envolvimento da equipe para seu êxito, exigindo a obediência de uma série de etapas que devem ser desenvolvidas e constantemente reavaliadas (LOVATTI, 2004). É necessário o aperfeiçoamento constante das ações de controle sanitário dos alimentos com objetivo de monitorar e minimizar os riscos originados pela ingestão de alimentos contaminados (FONSECA et al., 2010). Neste sentido, instrumentos legais como a Resolução - RDC no 275/2002 foram aprovados com o intuito de contribuir para melhoria do controle de qualidade na industrialização e processamento de alimentos (ANVISA, 2002).

Conduziu-se este estudo com o objetivo de avaliar a situação da implementação das boas práticas de fabricação, edificações, equipamentos e utensílios, documentação e outros itens relacionados na RDC 275/2002 (ANVISA, 2002) bem como as condições microbiológicas de uma agroindústria de pastifício, situada no oeste do Paraná, classificando-a em relação a qualidade, elencando os problemas encontrados e as possibilidades de melhorias a serem implantadas em um futuro próximo.

\section{MATERIAIS E MÉTODOS}

A empresa em estudo atua no ramo agroindustrial e está localizada na região oeste do estado do Paraná. Produz massas caseiras em geral, e massas recheadas, como massas de pastéis, macarrão, massas de lasanhas, tortéi canelone e lasanhas prontas. Além disso, também são produzidos pães. Os produtos são entregues pela própria empresa em mercados, mercearias e padarias da região. Este trabalho utilizou como metodologia de pesquisa o estudo de caso, para conhecer o fenômeno no contexto real de forma ampla e detalhada (YIN, 2001).

Neste estudo foram utilizados dois tipos de coleta de dados, a aplicação de uma lista de verificação para avaliação de boas práticas e a coleta de amostras para realização de análises microbiológicas. Para a 
avaliação das boas práticas da unidade de pastifício utilizou-se a lista de verificação, com base na Resolução RDC 275 de 21 de outubro de 2002 da ANVISA (2002). O preenchimento da lista de verificação se deu a partir de três opções de resposta: a) Sim, se o item verificado atende a legislação; b) Não, se o item avaliado encontra-se fora da conformidade; e a opção c) Não Aplicável, quando o item observado não fosse aplicável ao estabelecimento.

A lista de verificação foi preenchida por meio de observação visual no próprio local, juntamente com as informações fornecidas pelo proprietário. Nessa lista de verificação, constam 164 itens, agrupados por assunto em treze blocos subdivididos em: 1) Edificações e instalações; 2) Higienização de instalações; 3) Controle integrado de vetores e pragas urbanas; 4) Abastecimento de água; 5) Manejo de resíduos; 6) Equipamentos, móveis e utensílios; 7) Higienização dos equipamentos e maquinários, e dos móveis e utensílios; 8) Manipuladores; 9) Matéria-prima, ingredientes e embalagens; 10) Rotulagem e armazenamento do produto final; Exposição ao consumo do alimento preparado; 11) Controle de qualidade do produto final; 12) Transporte do produto final; e 13) Documentação. O resultado da avaliação da lista de verificação foi obtido através de um cálculo, onde se considerou o total de itens adequados multiplicados por cem, e dividiu-se pela quantidade total de itens avaliados, tendo assim o percentual de adequação (PA), como representado na Equação 1.

$$
P A=\frac{\text { Quantidade de itens adequados } .100}{\text { Total de itens avaliados }}
$$

Dessa forma, o estabelecimento pôde ser agrupado de acordo com o percentual dos itens em conformidade: Grupo 1: Bom (76 a 100 \% de itens atendidos); Grupo 2: Regular (51 a 75\% dos itens atendidos); Grupo 3: Ruim (0 a $50 \%$ dos itens atendidos).

As análises microbiológicas e a preparação dos meios de cultura foram realizadas no laboratório de microbiologia da instituição de filiação dos autores do estudo, após terem sido colhidas as amostras na indústria. Para a realização da coleta das amostras foi necessária uma preparação anterior dos materiais e dos meios de cultura a serem utilizados. Primeiramente determinou-se a quantidade de meio a ser preparado tendo em vista que para cada placa de Petri foram utilizados $25 \mathrm{~mL}$ de meio, para cada tubo pequeno com tampa de rosca $5 \mathrm{~mL}$ e para os demais tubos de ensaio $10 \mathrm{~mL}$. Para preparar os meios de cultivo adicionouse água deionizada, aos meios desidratados de acordo com a descrição que constava nas embalagens. Utilizou-se meios prontos, Ágar Batata Dextrose (BD), Ágar para Contagem Total ou Plate Count Agar (PCA) e solução para preparo de ADTP (Água Destilada Tamponada Peptonada), por meio da dissolução da quantidade indicada pelo fabricante por litro de água, tendo em vista a quantidade a ser preparada, para encontrar a quantidade de meio de cultivo a ser dissolvida (x), utilizou-se a Equação 2.

$$
\frac{\text { Grama de meio }}{x}=\frac{1000 \mathrm{ml}}{\text { Quantidade a ser preparada }(\mathrm{ml})}
$$

Pesou-se então a quantidade de meio em um Erlenmeyer e adicionou-se a água destilada necessária. As misturas foram então aquecidas para dissolução do ágar. Após dissolvidos os produtos, os Erlenmeyers 
foram identificados, tampados e embrulhados para realização da autoclavagem. Depois de autoclavados os meios foram plaqueados em câmara de fluxo laminar, que foi previamente preparada e higienizada.

A coleta das amostras foi realizada em uma indústria de pastifício. A mesma foi submetida a avaliações microbiológica das superfícies dos equipamentos e do ambiente. Como forma de garantia da qualidade, as amostras foram feitas em forma de duplicata, ou seja, foram retiradas duas amostras, ao mesmo tempo, de cada local. Os equipamentos dos quais foram retiradas as amostras foram: a masseira, que é utilizada para misturar os ingredientes e bater a massa (Figura 1A), a balança, (Figura 1B), que é utilizada para pesar as massas dos pães, o cilindro, usado para esticar as massas, (Figura 1C), a mesa 1, que é utilizada apenas na fabricação dos pães (Figura 1D), a mesa 2 que é utilizada para esticar as massas de macarrão e para as demais massas fabricadas, (Figura 1E) e o último equipamento foi a pia como mostra a Figura 1F. Para coletar a amostra dos equipamentos, começando com a Mesa 1 (Figura 1D), utilizou-se um delimitador de superfície, com área de $10^{2} \mathrm{~cm}^{2}$, conforme recomendado por Tondo (2014).

Retirou-se o Swab de sua embalagem e iniciou-se a coleta na área delimitada. Para isso utilizou-se a técnica de esfregaço de superfície empregando-se Swabs e seguindo-se as recomendações da APHA (American Public Health Association) descrita por Sveum et al. (1992). O Swab foi friccionado, formando um ângulo de $30^{\circ} \mathrm{com}$ a superfície, no sentido da esquerda para direita, de cima para baixo e em seguida o Swab foi transferido para tubos de ensaio com $5 \mathrm{~mL}$ de ADTP 0,12\% e colocado em uma bolsa térmica com gelo. Para coleta da amostra de contaminação do ambiente, primeiramente definiu-se um local, o qual foi a mesa 1 (Figura 1D), devido ao alto nível de utilização e por estar posicionada no centro da sala do setor de fabricação.
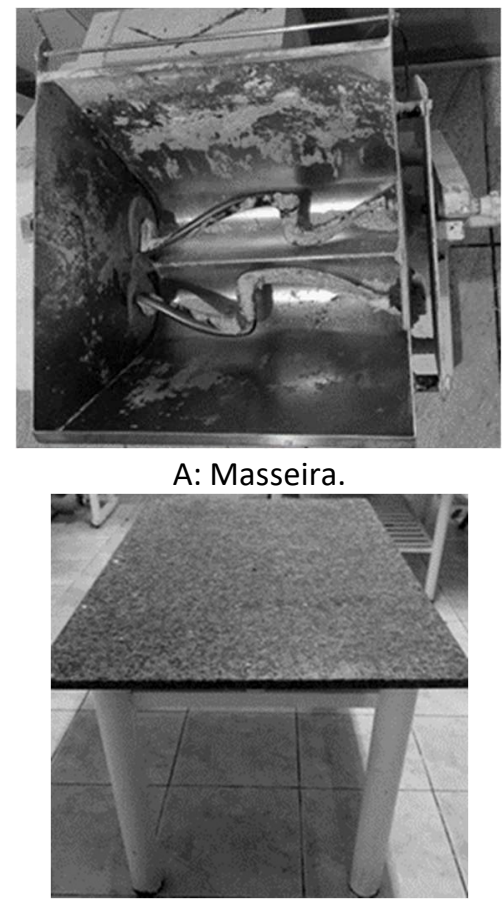

D: Mesa 1- Exclusiva para pães.

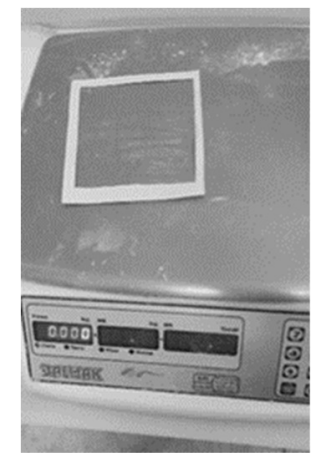

B: Balança.

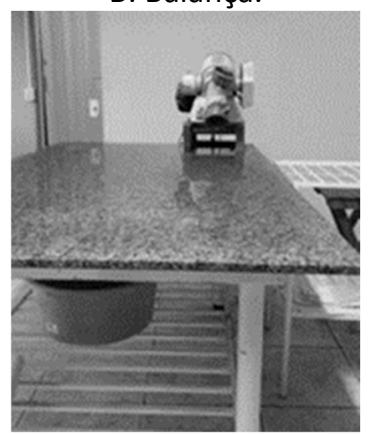

E: Mesa 2- Esticar macarrão.

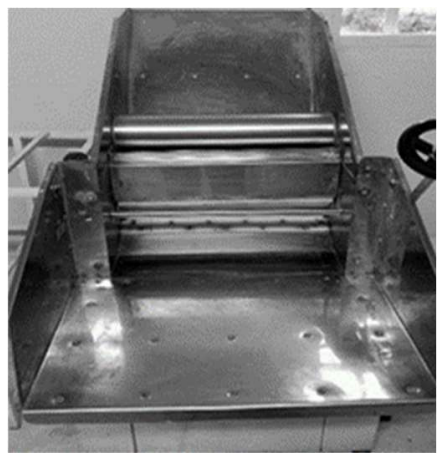

C: Cilindro

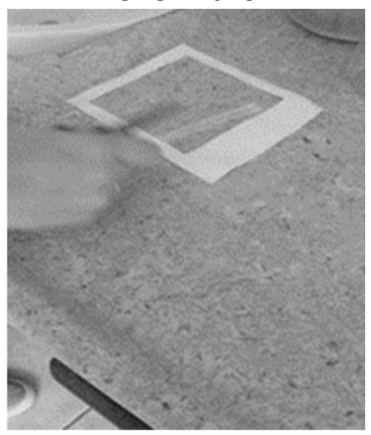

F: Pia 


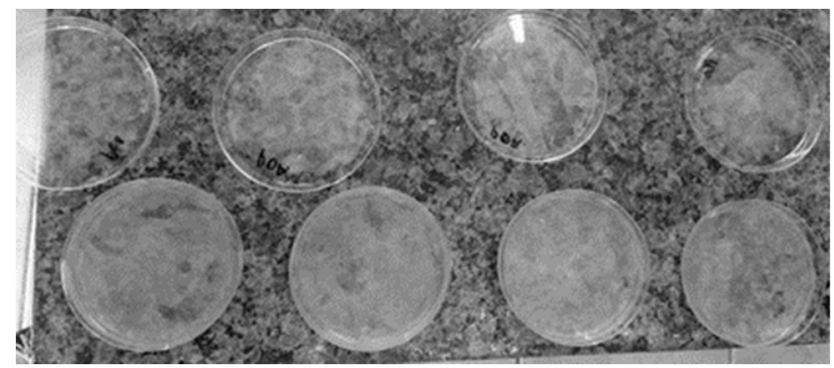

G: Amostra do ambiente na fase de coleta.

Figura 1: Equipamentos e Superfícies avaliados ao longo do estudo.

Feito isso utilizou-se quatro placas de Petri com o meio de cultura já estabelecido, duas com BD, e outras duas com PCA. Em seguida disponibilizou-se as placas na mesa 1, com uma altura de 80 centímetros por 15 minutos, como mostra a Figura 1G. Passados os 15 minutos as amostras foram colocadas dentro de uma bolsa térmica e posteriormente levadas novamente ao laboratório para incubação em estufas por tempos e temperaturas adequados os quais serão descritos na sequência.

Para continuação da análise dos materiais coletados por swab ao retornar ao laboratório, realizouse a identificação, através de uma caneta marcadora, das placas de Petri com o seu respectivo local de coleta da mesma forma que se tinha anotado nos tubos de coleta. Com auxílio de uma pipeta, coletou-se 0,1 mL das amostras e espalhou-se na placa de Petri utilizando uma alça de Drigalski esterilizada por autoclavagem e manipulado próximo a um bico de Bunsen.

A seguir as placas de Petri foram incubadas na estufa. Todas as amostras semeadas no meio de cultivo PCA ficaram na estufa por 48 horas e $36 \pm 1$ 으. Já as amostras com o meio de cultivo BD ficaram na estufa por 7 dias, $25 \pm 1$ ํㅡ. Após as 48 horas realizou-se a contagem das unidades formadoras de colônias de bactérias mesófilas aeróbias que se desenvolveram nas placas de Petri com o meio de cultura PCA. Depois de 7 dias realizou-se a contagem dos bolores e leveduras que cresceram nas placas de Petri com o meio de cultura BD.

Para realizar uma análise das amostras, foram feitos cálculos utilizando a quantidade de UFC (Unidades Formadoras de Colônia) observadas, a olho nu, em cada Placa de Petri. Como parâmetro utilizouse os valores limites estipulados pelo Decreto-Lei no 79/2006 (PORTUGAL, 2006) de 4 de abril presente no Artigo 29 e também os da NASA e APHA (EVANCHO et al., 2001). Os cálculos para a obtenção das UFC dos equipamentos foram feitos utilizando as Equações 4 e 5 . Considerando que o número de colônias identificadas por amostra foi dado a partir de 0,1 mL de ADTP, e que no tubo de ensaio onde se realizou a coleta havia $5 \mathrm{~mL}$ de ADTP, a transformação descrita na Equação 3 se faz necessária. Posteriormente o uso da Equação 4 proporciona a obtenção do número de UFC por unidade de área avaliada.

$$
\begin{gathered}
\frac{(n-\text { o de UFC na placa } * 5 \mathrm{ml})}{0,1 \mathrm{ml}}=X U F C \\
\frac{\left(X U F C * 1 \mathrm{~cm}^{2}\right)}{100 \mathrm{~cm}^{2}}=Y U F C / \mathrm{cm}^{2}
\end{gathered}
$$


Para os cálculos da quantidade de microrganismos presentes no ambiente foram utilizadas as Equações 5 e 6. De acordo com o Decreto lei 79/2006 - Artigo 29, parágrafo 8b (PORTUGAL, 2006) a quantidade máxima tolerada para bolores, leveduras e bactérias é de $500 \mathrm{UFC} / \mathrm{m}^{3}$. A fórmula para cálculo está apresentada na Equação 5.

$$
\frac{n^{\circ} U F C \text { na placa }}{\text { área da placa }\left(m^{2}\right)} * \frac{1}{23 m} \frac{U F C}{m^{3}}
$$

A NASA e APHA (EVANCHO et al., 2001), apresentam a Equação 6 para o cálculo do número de UFC por área no tempo avaliado que foi de 15 minutos.

$$
\frac{\frac{U F C}{c m^{2}}}{15 m_{i n}}=\frac{n^{\circ} U F C \text { na placa }}{\text { Área da placa }\left(\mathrm{cm}^{2}\right)}
$$

Sendo que a área da placa tanto na Equação 5 como na 6 pode ser obtida por $\pi * r^{2}=\pi *(d / 2)^{2}$.

\section{RESULTADOS E DISCUSSÃO}

Após o preenchimento da lista de verificação das boas práticas de fabricação em estabelecimentos produtores/industrializadores de alimentos, verificou-se 141 itens avaliados sendo que os demais não se aplicavam ao ambiente da indústria estudada. Entre eles 59 não atenderam aos pré-requisitos da RDC 275 (ANVISA, 2002), e os demais 82 itens apresentaram-se em conformidade com a legislação, e corresponderam a aproximadamente $58 \%$ dos itens avaliados.

Fez-se na sequência uma discussão com base nos conhecimentos de boas práticas para a opção por estratégias institucionais de intervenção (ANVISA, 2002; SACCOL et al., 2006). Nesse contexto a empresa se enquadrou no Grupo 2, pois está dentro da faixa de $51 \%$ e $75 \%$, e se encontra em situação 'regular' de acordo com a classificação da RDC. A Tabela 1 apresenta os resultados referentes aos 141 itens que foram agrupados por assunto, em treze blocos, mostrando a quantidade de itens avaliados e o percentual que está em situa ção adequada. O cálculo das porcentagens (PA) fez-se utilizando a Equação 1 citada na metodologia.

Cabe destacar que inadequações em itens tais como: manipuladores, abastecimento de água e higienização das instalações, possuem grandes probabilidades de ocasionar riscos à segurança dos alimentos produzidos, mesmo que não estejam com os mais elevados percentuais de inadequação.

\begin{tabular}{|c|c|c|c|}
\hline Itens & Descrição & Itens avaliados & $\%$ adeq. \\
\hline 1 & Edificações e instalações & 43 & 30,23 \\
\hline 2 & Higienização das instalações & 9 & 77,78 \\
\hline 3 & Controle integrado de vetores e pragas urbanas & 3 & 67 \\
\hline 4 & Abastecimento de água & 10 & 50 \\
\hline 5 & Manejo dos resíduos & 5 & 80 \\
\hline 6 & Equipamentos, móveis e utensílios. & 12 & 75 \\
\hline 7 & Higienização dos equipamentos e máquinas, e dos móveis e utensílios. & 9 & 77,78 \\
\hline 8 & Manipuladores & 14 & 50 \\
\hline 9 & Matéria-prima, ingredientes e embalagens. & 14 & 92,86 \\
\hline 10 & Rotulagem e armazenamento & 18 & 61,11 \\
\hline 11 & Controle de qualidade do produto final & 4 & 25 \\
\hline 12 & Transporte do produto final & 5 & 80 \\
\hline 13 & Documentação & 9 & 11,11 \\
\hline
\end{tabular}

Tabela 1: Percentual de adequação do estabelecimento analisado de acordo com os itens avaliados. 
Para a melhoria de alguns blocos de itens que se encontram inadequados propõe-se a tomada de algumas medidas. Para higiene pessoal dos manipuladores e requisitos sanitários recomenda-se a fixação na parede de avisos educativos, tais como placas de lixo, proibido fumar, entrada proibida, e a realização de um cronograma para os exames periódicos, arquivando os registros de saúde. Além disso, deve-se realizar a capacitação técnica dos proprietários para que possam cobrar com maior eficácia o trabalho dos manipuladores, para que os mesmos se conscientizem e preocupem-se com a garantia da qualidade dos alimentos produzidos.

Em relação ao abastecimento de água observou-se que este é realizado por ligação a rede pública de abastecimento, o que faz com que a garantia de potabilidade da água utilizada seja transferida para empresa que a fornece. No caso do estado do Paraná está empresa é a Sanepar, a qual possui laboratório onde analisa e atesta a qualidade da água fornecida, bem como técnicos responsáveis pela potabilidade. Porém, a parte da higienização do reservatório de água da empresa, em relação a registros, planilha de trocas de elementos filtrantes, periodicidade da limpeza do reservatório, bem como existência de responsável pela execução dessa limpeza estavam ausentes.

Recomenda-se que a empresa tome providências em relação aos quesitos de sua responsabilidade pois a água tem grande possibilidade de contaminar tanto os alimentos quanto o ambiente e equipamentos. O uso de água de má qualidade pode contaminar ao invés de higienizar, sendo esse um item de primordial importância quando se trata de saúde e segurança dos alimentos.

Quanto à documentação e ao registro das atividades, de acordo com o Ministério da Agricultura e do Abastecimento, por apresentar um risco inerente ao alimento, deve-se manter registros apropriados da elaboração, produção e distribuição. Logo, sugere-se a criação de alguns POPs (Procedimentos Operacionais Padrão) para a limpeza de bancadas, pias, pisos e paredes, além da correta lavagem de mãos e higienização dos utensílios, uma vez que a empresa não possui esses documentos para padronizar e esclarecer os procedimentos a serem adotados durante a execução de suas atividades.

Com a finalidade de garantir uma higienização adequada na área de manipulação de alimentos, o Ministério da Agricultura regularizou através da portaria 368/97 (ANVISA, 1997) como deve ser feita a construção de portas, janelas, pisos, paredes, entre outros. Sendo assim, a empresa deveria adotar estas reformas para a melhoria da estrutura do estabelecimento, não esquecendo a sua frequente manutenção. As paredes devem ser revestidas com materiais laváveis e cor clara, lisas e de fácil limpeza e desinfecção, portanto deve-se fazer a colocação de azulejos brancos na parede do banheiro. Além disso, deve-se fazer a substituição das lixeiras por novas que tenham acionamento com o pé, evitando assim o contato com a mão do manipulador.

As janelas devem ser ajustadas de forma que não haja acúmulo de sujidades, e possuir telas de proteção milimétricas bem conservadas, para estando, recomenda-se fazer a substituição das janelas e a colocação de novas telas. Portas devem ser lisas, de fácil limpeza, ajustadas aos batentes e sem falhas de revestimento, em adequado estado de conservação, e com telas de proteção milimétricas bem conservadas, 
sendo assim, as portas também deverão ser substituídas e realizadas a colocação de novas telas. Nas lâmpadas deve-se colocar um sistema de proteção contra queda ou explosão, evitando assim que caiam pedaços de plásticos ou vidro sobre o alimento.

A ventilação e iluminação também devem ser melhoradas. O local não conta com um sistema de exaustão, para renovação de ar dos ambientes fechados, tornando-se extremamente quente para os manipuladores que trabalham constantemente com fornos. Tal fato propicia ainda a proliferação de fungos e bactérias. Sugere-se a implantação de um sistema de exaustão, para manter o ambiente de produção livre de fumaça e odores, garantindo uma renovação de ar constante, melhorando qualidade dos alimentos manipulados.

Os utensílios e equipamentos não possuem uma microflora própria, sendo um reflexo dos cuidados tidos na sua limpeza e manutenção. Tendo em vista que os microrganismos aderem facilmente aos materiais, o contato dos alimentos com superfícies mal limpas, aumenta consideravelmente a sua carga microbiana. Máquinas, acessórios e utensílios que não estejam devidamente limpos são inevitavelmente fontes de contaminação. É fundamental que os utensílios não sejam utilizados para manipular ou guardar alimentos diferentes, de modo a evitar as contaminações cruzadas.

A fim de ratificar as observações feitas com a aplicação da lista de verificação, realizou-se as análises microbiológicas. As análises das amostras, colhidas em duplicatas para os dois tipos de microrganismos avaliados, foram realizadas de forma independente.

Assim foi possível obter maior precisão dos resultados de UFC (Unidades Formadoras de Colônia) das áreas em questão. Após serem mantidas na estufa pelo tempo e temperatura pré-determinados, as placas de Petri foram posicionadas sobre a bancada do laboratório de microbiologia onde realizou-se a contagem e efetivação dos cálculos necessários, de onde obteve-se os valores apresentados nas Tabela 2 e 3.

Tabela 2: Contagem de microrganismos em UFC/ $\mathrm{cm}^{2}$ para superfícies e equipamentos.

\begin{tabular}{lllll}
\hline Equipamentos/ & \multicolumn{3}{l}{ Bactérias } & \multicolumn{2}{l}{ Bolores e Leveduras } \\
\cline { 2 - 5 } Superfícies & Amostra 1 & Amostra 2 & Amostra 1 & Amostra 2 \\
\hline Cilindro & $1 \mathrm{UFC} / \mathrm{cm}^{2}$ & $1,3 \times 10 \mathrm{UFC} / \mathrm{cm}^{2}$ & $0,5 \mathrm{UFC} / \mathrm{cm}^{2}$ & $1,15 \times 10 \mathrm{UFC} / \mathrm{cm}^{2}$ \\
Balança & $<2 \mathrm{UFC} / \mathrm{cm}^{2}$ & $0,5 \mathrm{UFC} / \mathrm{cm}^{2}$ & $1,5 \mathrm{UFC} / \mathrm{cm}^{2}$ & $2,5 \mathrm{UFC} / \mathrm{cm}^{2}$ \\
Mesa 1 & $<2 \mathrm{UFC} / \mathrm{cm}^{2}$ & $0,5 \mathrm{UFC} / \mathrm{cm}^{2}$ & $1,5 \mathrm{UFC} / \mathrm{cm}^{2}$ & $0,5 \mathrm{UFC} / \mathrm{cm}^{2}$ \\
Mesa 2 & $<2 \mathrm{UFC} / \mathrm{cm}^{2}$ & $4 \mathrm{UFC} / \mathrm{cm}^{2}$ & $0,5 \mathrm{UFC} / \mathrm{cm}^{2}$ & $1 \mathrm{UFC} / \mathrm{cm}^{2}$ \\
Masseira & $<2 \mathrm{UFC} / \mathrm{cm}^{2}$ & $0,5 \mathrm{UFC} / \mathrm{cm}^{2}$ & $<2 \mathrm{UFC} / \mathrm{cm}^{2}$ & $1 \mathrm{UFC} / \mathrm{cm}^{2}$ \\
Pia & $1,75 \times 10 \mathrm{UFC} / \mathrm{cm}^{2}$ & $1,225 \times 10^{2} \mathrm{UFC} / \mathrm{cm}^{2}$ & $6,2 \times 10 \mathrm{UFC} / \mathrm{cm}^{2}$ & $5,2 \times 10 \mathrm{UFC} / \mathrm{cm}^{2}$ \\
\hline
\end{tabular}

Tabela 3: Contagem de microrganismos nas unidades de UFC $/ \mathrm{m}^{3}$ e UFC $/ \mathrm{cm}^{2} / \mathrm{sem}$ para o ambiente interno da empresa.

\begin{tabular}{lllll}
\hline \multirow{2}{*}{ Local } & Bactérias & \multicolumn{3}{l}{ Bolores e Leveduras } \\
\cline { 2 - 5 } & Amostra 1 & Amostra 2 & Amostra 1 & Amostra 2 \\
\hline Sobre a Mesa 1 & $6,15 \times 10^{2} \mathrm{UFC} / \mathrm{m}^{3}$ & $3,60 \times 10^{2} \mathrm{UFC} / \mathrm{m}^{3}$ & $2,87 \times 10^{3} \mathrm{UFC} / \mathrm{m}^{3}$ & $2,05 \times 10^{3} \mathrm{UFC} / \mathrm{m}^{3}$ \\
Sobre a Mesa 1 & $9,50 \times 10^{2} \mathrm{UFC} / \mathrm{cm}^{2} / \mathrm{sem}$ & $6,27 \times 10^{2} \mathrm{UFC} / \mathrm{cm}^{2} / \mathrm{sem}$ & $5,07 \times 10^{3} \mathrm{UFC} / \mathrm{cm}^{2} / \mathrm{sem}$ & $3,17 \times 10^{3} \mathrm{UFC} / \mathrm{cm}^{2} / \mathrm{sem}$ \\
\hline
\end{tabular}

Ao realizar a contagem, verificou-se que algumas placas não possuíam UFC visíveis a olho nu. Nesse caso considerou-se que essas análises apresentaram limites menores que os previstos pela legislação mais exigente $\left(<2 \mathrm{UFC} / \mathrm{cm}^{2}\right)$. As demais placas, onde se pode perceber a presença de uma ou mais UFC, fez-se a contagem para dar continuidade a análise laboratorial.

De acordo com Coelho et al. (2010), a APHA recomenda contagens de até 2 UFC/ $\mathrm{cm}^{2}$ para superfícies 
de bancadas e $10^{2} \mathrm{UFC} / \mathrm{cm}^{2}$ utensílios ou área amostrada de equipamentos, a legislação brasileira não estabelece limites para contagem de microrganismos em superfícies de processamento de alimentos. Pela dificuldade de adequação ao padrão americano, alguns pesquisadores e instituições admitem contagens superiores. Silva Júnior (2001), preconiza uma contagem menor ou igual a $5 \times 10 \mathrm{UFC} / \mathrm{cm}^{2}$ para equipamentos, utensílios ou superfícies em razão principalmente das condições de temperatura ambiental no Brasil.

Com os números de UFC por amostra de cada placa de Petri com os ágares PCA e BD e seus respectivos limites de tolerância para superfícies/equipamentos, foi possível iniciar os cálculos de análise através das Equações 3 e 4 descritas na metodologia. Substituindo o valor de UFC por placa, chegando-se aos resultados apresentado na Tabela 2.

Percebe-se que, segundo Andrade et al. (2003), apenas a segunda amostra com PCA para superfície da pia encontrou-se acima dos limites tolerados por algumas instituições e pesquisadores os quais indicam até $5 \times 10 \mathrm{UFC} / \mathrm{cm}^{2}$. Ao analisar os valores a partir de NASA endossado pela APHA (EVANCHO et al., 2001), verifica-se que uma amostra da mesa 2 ultrapassa o valor máximo de $2 \mathrm{UFC} / \mathrm{cm}^{2}$ de bactérias por superfície e a pia também se encontra acima desse valor, dessa vez nas duas amostras coletadas.

Em relação aos limites estabelecidos pela NASA endossado pela APHA (EVANCHO et al., 2001), podese considerar que as amostras da pia se mantiveram acima do limite tolerado também para bolores e leveduras, sendo que ambas ultrapassaram o limite de $2 \mathrm{UFC} / \mathrm{cm}^{2}$ preconizado para superfícies. Nenhum dos equipamentos avaliados mostraram-se acima de $10^{2} \mathrm{UFC} / \mathrm{cm}^{2}$, limite estabelecido para eles quando se avaliou a contagem de bolores e leveduras.

Com esses resultados, comprova-se que as condições higiênicas da empresa de panificação podem ser melhoradas, uma vez que, essa contaminação pode ser decorrente da má higienização das superfícies, principalmente da pia. Além disso, observou-se que alguns manipuladores traziam alimentos de fora para dentro da área de produção, deixando-os sobre a pia, o que pode aumentar os riscos de contaminação cruzada e justificar os resultados elevados obtidos na análise microbiológica desta superfície. A simples eliminação do uso da pia para outras atividades que não a de interesse da empresa pode ajudar na redução desse problema.

Jesus et al. (2007), afirmam que, de acordo com a APHA (American Public Health Association), os ambientes são considerados em condições higiênicas satisfatórias e adequados ao processamento de alimentos quando apresentam uma contagem de microrganismos mesófilos aeróbios de até $3 \times 10 \mathrm{UFC} / \mathrm{cm}^{2} / \mathrm{semana}$. No entanto, muitas vezes está recomendação americana é considerada rígida para os estabelecimentos brasileiros. De acordo com o decreto de lei 79/2006 (PORTUGAL, 2006), as concentrações máximas de referência de poluentes toleradas no interior dos edifícios para microrganismos são de $5 \times 10^{3}$ unidades formadoras de colónias (UFC), sendo detectados bactérias e fungos.

Com os números de UFC por amostra de placa de Petri com PCA e BD, e seus respectivos limites de tolerância no ambiente, foi possível iniciar os cálculos de análise. Substituindo o valor de UFC por placa nas 
Equações 5 e 6, apresentadas na metodologia, chega-se aos resultados apresentados na Tabela 3. Percebese que, para os dois parâmetros utilizados, a superfície apresenta-se contaminada em pelo menos uma das amostras, com valores acima dos preconizados. Assim como na análise das amostras das placas de Petri com PCA, as amostras com BD também se apresentaram acima dos limites, porém, nesse caso, em todas as amostras. Pode-se considerar que o ambiente possui um nível de contaminação superior aos parâmetros pré-estabelecidos pelos autores apresentados.

A análise geral das amostras de superfícies e equipamentos é necessária para que se determine a existência de fontes poluidoras, onde, muitas vezes, não são detectáveis e visíveis a olho nu. Os resultados obtidos podem ser consequência da entrada de insetos no ambiente, seja através dos ralos sem proteção, portas e janelas com vedação insuficiente, sistemas de fechamento das portas inadequado, ou local onde 0 encanamento adentra no ambiente sem proteção.

Como a superfície da mesa é de granito isso pode facilitar a incrustação de sujeiras e formação de biofilmes. Além disso, os resultados acima do limite comprovam que a higienização das superfícies está sendo realizada de forma incorreta, isso pode ser decorrente do fato da empresa não ter registros da forma correta de realizar os procedimentos de limpeza (POPs), e a mesma não ser realizada com uma frequência préestabelecida.

Cabe destacar que a verificação de ambientes de processamento de alimentos e percepção de alguns problemas tem sido relatada em outros trabalhos (COELHO et al., 2010; ANDRADE et al., 2003; SOARES et al., 2018), essa situação não é, portanto, incomum em nosso país, dessa forma trabalhos dessa natureza se fazem importantes, na busca da melhoria da segurança alimentar e redução da possibilidade de ocorrência de surtos de toxinfecção alimentar, um sério problema econômico e de saúde pública.

\section{CONCLUSÕES}

Em alguns pontos avaliados a contaminação esteve acima dos limites recomendados, comprovando que a melhoria nas boas práticas de manipulação, bem como em alguns pontos já elencados neste estudo se fazem necessárias para a indústria de pastifício acompanhada.

Com a aplicação da lista de verificação das boas práticas de fabricação, pode-se constatar que são vários os quesitos necessários para se oferecer um alimento seguro e de qualidade. A contribuição do estudo para a saúde, especialmente no que diz respeito à segurança alimentar fica implícita, pois, além de se garantir alimentos suficientes para todos, estes precisam ter sua qualidade assegurada em relação aos aspectos físicos, químicos e microbiológicos, devendo ser produzidos com base em práticas alimentares saudáveis, de forma a contribuir para uma existência digna e integral da pessoa humana.

A classificação da empresa foi a intermediária, descrita como 'regular', enquadrada pela legislação no Grupo 2. Para melhorar sua classificação precisará fazer mudanças significativas, principalmente nos itens documentação, controle de qualidade do produto final, edificações, instalações, manipuladores e abastecimento de água. Essas melhorias devem ser contínuas e em um processo gradual, somente assim se garante que as 
normas e regras estabelecidas serão cumpridas, deixando de ser uma obrigação e tornando-se um procedimento de rotina.

\section{REFERÊNCIAS}

ANDRADE, N. J.; SILVA, R. M. M.; BRABES, K. C. S.. Avaliação das condições microbiológicas em unidades de alimentação e nutrição. Ciênc. Agrotec., v.27, n.3, p.590-596, 2003. DOI: http://dx.doi.org/10.1590/S1413-70542003000300014

ANVISA. Agência Nacional de Vigilância Sanitária. Resolução RDC n. 368, de 04 de setembro de 1997. Regulamento Técnico sobre as condições Higiênico Sanitárias e de Boas Práticas de Fabricação para Estabelecimentos Elaboradores/Industrializadores de Alimentos. Brasília: DOU, 1997.

ANVISA. Agência Nacional de Vigilância Sanitária. Resolução RDC $\mathbf{n}$. 275, de 21 de outubro de 2002. Dispõe sobre o Regulamento Técnico de Procedimentos Operacionais Padronizados aplicados aos Estabelecimentos Produtores/Industrializadores de Alimentos e a Lista de Verificação das Boas Práticas de Fabricação em Estabelecimentos Produtores/Industrializadores de Alimentos. Brasília: DOU, 2002.

ANVISA. Agência Nacional de Vigilância Sanitária. Resolução RDC $\mathbf{n}$. 216, de 15 de setembro de 2004. Dispõe sobre Regulamento Técnico de Boas Práticas para Serviços de Alimentação. 2004. Brasília: DOU, 2004.

BRASIL. Resolução RDC. n. 263, de 22 de setembro de 2005. Regulamento Técnico. Brasília: DOU, 2005.

COELHO, A. I. M.; MILAGRES, R. C. R. M.; MARTINS, J. F. L.; AZEREDO, R. M. C.; SANTANA, A. M. C.. Contaminação microbiológica de ambientes e de superfícies em restaurantes comerciais. Ciênc. Saúde Coletiva, Rio de Janeiro, v.15, n.1, p.1597-1606, 2010. DOI: http://dx.doi.org/10.1590/S1413-81232010000700071

DANTAS, R. L.; LIMA, C. A. P.; ROCHA, A. P. T.. Análise sensorial e microbiológica de massa alimentícia mista estabilizada. In: ENCONTRO NACIONAL DE EDUCAÇÃO, CIÊNCIA E TECNOLOGIA, 1. Anais. Campina Grande: Realize, 2012.

DEINA, C.; SCHMIDT, C. A. P.. Previsões Estatísticas: Estudo do Cenário do Trigo no Estado do Paraná. Riga Letônia: Novas Edições Acadêmicas, 2018.

EVANCHO, G. M.; SVEUM, W. H.; MOBERG, L. J.; FRANK, J. F.. Microbiological monitoring of the food-processing environment. In: DOWNES, F. P.; ITO, K.. Compendium of methods for the microbiological examination of foods. 4 ed. Washington: APHA, 2001. p.25-36.

FONSECA, M. P.; MANFRIDINI, L. A.; SÃO JOSÉ, J. F. B.; TOMAZINI, A. P. B.; MARTINI, H. S. D.; RIBEIRO, R. C. L.; SANT'ANA, H. M. P.. Avaliação das condições físicofuncionais de restaurantes comerciais para implementação das boas práticas. Alim. Nutr. Araraquarav., v.21, n.2, p.251257, 2010.
FORSYTHE, S. J.. Microbiologia da segurança dos alimentos. Porto Alegre: ArtMed, 2013.

GOMES, H. V.; RODRIGUES, R. K.. Boas Práticas de Fabricação na Indústria de Panificação. In: ENCONTRO NACIONAL DE ENGENHARIA DE PRODUÇÃO, 26. Anais. Rio de Janeiro: ABEPRO, 2006

GUARIENTI, E. M.; MIRANDA, M. Z.. Massa fresca tipo capelete congelada. Brasília: Embrapa Informação Tecnológica, 2007

JESUS, I. A.; CASTRO, A. M. V.; QUEIROZ, A. L. M.; ARAÚJO, E. L. B.; NASCIMENTO, G. S. M.; VASCONCELOS, M. A. A.; CABRAL, T. M. A.; NASCIMENTO, G. J.. Qualidade Higiênico sanitário do Ar de Ambientes de Algumas Indústrias de Alimentos do Município de João Pessoa/PB. In: ENCONTRO DE INICIAÇÃO A DOCÊNCIA, 10. Anais. 2007.

LOURENÇO, J. C.. Logística agroindustrial: desafios para o Brasil na primeira década do século XXI. João Pessoa: Enciclopédia Virtual, 2010.

LOVATTI, R. C. C.. Gestão da qualidade em alimentos: uma abordagem prática. Hig. Alim. São Paulo, v.18, n.125, p.9093, 2004.

MADIGAN, M. T.; MARTINKO, J. M.; BENDER, K. S.; BUCKLEY, D. H.; STAHL, D. A.. Microbiologia de Brock. 14 ed. Porto Alegre: Artmed, 2016.

PORTUGAL. Decreto-Lei n. 79/2006. Sistema nacional de certificação energética e da qualidade do ar interior nos edifícios. Série I-A. N. 67. Diário de República, 2006.

SACCOL, A. L. F.; HECKTHEUER, L. H.; RICHARDS, N. S.; STANGARLIN, L.. Lista de avaliação de boas práticas para serviços de alimentação: RDC 216. São Paulo: Varela, 2006.

SILVA JÚNIOR, E. A.. Manual de controle higiênico-sanitário em alimentos. 4 ed. São Paulo: Varela, 2001.

SOARES, D. S. B.; HENRIQUES, P.; FERREIRA, D. M.; DIAS, P. C.; PEREIRA, S.; BARBOSA, R. M. S.. Boas Práticas em Unidades de Alimentação e Nutrição Escolares de um município do estado do Rio de Janeiro, Brasil. Cien. Saúde Colet., Rio de Janeiro, v.23, n.12, p.4077-4083, 2018. DOI: http://dx.doi.org/10.1590/1413-812320182312.23992016

SVEUM, W. H.; MOBERG, L. J.; RUDE, R. A.; FRANK, J. F.. Microbiological monitoring of the food-processing environment. In: VANDERZANT, C.; SPLITTSTOESSER, D. F. Compendium of methods for the microbiological examination of foods. 3 ed. Washington: APHA, 1992. p.5174.

TONDO, E. C.. Monitoramento ambiental na produção de alimentos. Campinas: Universidade Federal do Rio Grande 
do Sul, Instituto de Ciência e Tecnologia de Alimentos.

Palestra no Workshop Food Safety, 2014.

TOLEDO, J. C.; BATALHA, M. O.; AMARAL, D. C.. Qualidade na indústria agroalimentar: situação atual e perspectivas.

Revista de Administração de Empresas, v.40, n.2, p.90-101, 2000.
VIALTA, A.; MORENO, I.; VALLE, J. L. E.. Boas práticas de fabricação, higienização e análise de perigos e pontos críticos de controle na indústria de laticínios: 1 - Requeijão. Rev. Ind. Lat., n.37, 2002.

YIN, R. K.. Estudo de caso: planejamento e métodos. Porto Alegre: Bookman, 2001.

A CBPC - Companhia Brasileira de Produção Científica (CNPJ: 11.221.422/0001-03) detém os direitos materiais desta publicação. Os direitos referem-se à publicação do trabalho em qualquer parte do mundo, incluindo os direitos às renovações, expansões e disseminações da contribuição, bem como outros direitos subsidiários. Todos os trabalhos publicados eletronicamente poderão posteriormente ser publicados em coletâneas impressas sob coordenação da Sustenere Publishing, da Companhia Brasileira de Produção Científica e seus parceiros autorizados. Os (as) autores (as) posteriormente ser publicados em coletâneas impressas sob coordenação da Sustenere Publishing, da Companhia Brasileira de Produção Cientifica e seus parce
preservam os direitos autorais, mas não têm permissão para a publicação da contribuição em outro meio, impresso ou digital, em português ou em tradução. 